\title{
Identification of decomposition volatile organic compounds from surface- deposited and submerged porcine remains
}

\author{
Irish L. ${ }^{\mathrm{a}, *}$, Rennie S.R. ${ }^{\mathrm{b}}$, Parkes G.M.B. ${ }^{\mathrm{c}}$, Williams A., ${ }^{\mathrm{c}, *}$ \\ ${ }^{a}$ Defence Science and Technology Laboratory, Fort Halstead, Sevenoaks, Kent TN14 7BP, United Kingdom of Great Britain and Northern Ireland \\ ${ }^{\mathrm{b}}$ Liverpool John Moores University, Byrom Street, Liverpool L3 3AF, United Kingdom of Great Britain and Northern Ireland \\ ${ }^{\mathrm{c}}$ School of Applied Sciences, University of Huddersfield, Huddersfield HD1 3DH, United Kingdom of Great Britain and Northern Ireland
}

\section{A R T I C L E I N F O}

\section{Keywords:}

Cadaver dogs

GC-MS

VOCs

Decomposition

Porcine remains

Drowning

\begin{abstract}
A B S T R A C T
Cadaver dogs are routinely used internationally by police and civilian search organisations to locate human remains on land and in water, yet little is currently known about the volatile organic compounds (VOCs) that are released by a cadaver underwater; how this compares to those given off by a cadaver deposited on land; and ultimately, how this affects the detection of drowned victims by dogs. The aim of this study was to identify the VOCs released by whole porcine (Sus scrofa domesticus) cadavers deposited on the surface and submerged in water using solid phase microextraction gas chromatography mass spectrometry (SPME GC-MS) to ascertain if there are notable differences in decomposition odour depending on the deposition location.

For the first time in the UK, the volatile organic compounds (VOCs) from the headspace of decomposing porcine cadavers deposited in both terrestrial and water environments have been detected and identified using SPME-GCMS, including thirteen new VOCs not previously detected from porcine cadavers. Distinct differences were found between the VOCs emitted by porcine cadavers in terrestrial and water environments. In total, seventy-four VOCs were identified from a variety of different chemical classes; carboxylic acids, alcohols, aromatics, aldehydes, ketones, hydrocarbons, esters, ethers, nitrogen compounds and sulphur compounds. Only forty-one VOCs were detected in the headspace of the submerged pigs with seventy detected in the headspace of the surface-deposited pigs. These deposition-dependent differences have important implications for the training of cadaver dogs in the UK. If dog training does not account for these depositional differences, there is potential for human remains to be missed.

Whilst the specific odours that elicit a trained response from cadaver dogs remain unknown, this research means that recommendations can be made for the training of cadaver dogs to incorporate different depositions, to account for odour differences and mitigate the possibility of missed human remains operationally.
\end{abstract}

\section{Introduction}

In the UK alone, there were over 380 accidental drownings in the year 2013 [1], with drowning claiming the lives of over 370,000 people worldwide each year [2]. Human remains may become submerged for a number of other reasons including suicides, disposal of homicide victims and in the aftermath of natural and man-made disasters [3]; therefore, techniques for the location of submerged human remains are of upmost importance for body recovery, subsequent identification and closure for the individual's family [4,5].

The decomposition process of deceased human and animal remains is a complex process that involves the breakdown of carbohydrates, proteins and fats into their constituents [6]. This includes a class of compounds known as volatile organic compounds (VOCs) which are odourous and readily detectable. Their production throughout the decomposition process is described below. VOCs are thought to be the chemicals responsible for attracting necrophagous insects that feed upon cadavers [7]. VOCs are also thought to be the chemicals which are detected by dogs trained to locate human remains [8], these dogs are known as cadaver or victim recovery (VR) dogs. An appreciation of the production of VOCs as a result of decomposition in different deposition conditions and over time can be used to assist the training of VR dogs.

\subsection{VOCs from the decomposition of carbohydrates}

Carbohydrates are broken down into their constituent sugars and

\footnotetext{
* Corresponding authors.

E-mail addresses: lirish@dstl.gov.uk (L. Irish), S.R.Rennie@2009.ljmu.ac.uk (S.R. Rennie), g.m.b.parkes@hud.ac.uk (G.M.B. Parkes), a.williams@hud.ac.uk (A. Williams).
} 
organic acids in the early stages of decomposition, due to cessation of the Krebs cycle, causing a reduction of $\mathrm{pH}$ within the body [9]. Under aerobic conditions, such as surface deposition, microbes can completely oxidise sugars into carbon dioxide and water via the intermediate products such as pyruvic acid and lactic acid and the alcohol, ethanol [10]. The breakdown of pyruvic acid results in a variety of products including ethanol, butanol, acetone butanoic acid, propionic acid, acetic acid, formic acid, lactic acid, propane-1,3-diol, propane-1,2-diol and butane-2,3-diol [6]. Reactive oxygen species (ROS) will also oxidise sugars to ketones [11].

Conversely, under anaerobic conditions, such as under water, incomplete oxidation of carbohydrates yields a variety of organic acids and alcohols. For example, many bacteria and yeast under anaerobic conditions will produce ethanol from carbohydrates [12], whereas fungi will decompose carbohydrates into organic acids [13]. Products of bacterial and fungal carbohydrate fermentation and anaeorobic decomposition include lactic acid, butanoic acid, acetic acid, ethanol, butanol and acetone [14].

Once the preferred substrate, glucose, is exhausted, bacteria will use alternative substrates. This explains why certain VOCs, such as ethanol, are observed during the early stages of decomposition, when glucose is still available. Under increasingly anaerobic conditions [6,14], these by-products become less prevalent, and other VOCs become apparent at later stages of decomposition [6].

\subsection{VOCs from the decomposition of proteins}

After death, the body's proteins are broken down by the process of proteolysis [9]. The first to be digested are the proteins of neuronal and epithelial tissues, followed by muscle proteins, the epidermis and collagen [15]. Proteolysis yields proteoses, peptones, polypeptides and amino acids, and ultimately results in the production of inorganic and organic gases distinctive to the decomposition process including ammonia, methane, hydrogen sulphide and carbon dioxide [15]. The rate of proteolysis is dependent on temperature, moisture and the bacteria present [15].

Proteins may be decarboxylated or deaminated. Decarboxylation is the process involving the removal of the carboxyl terminus of an amino acid and results in the production of biogenic diamines such as cadaverine and putrescine. Cadaverine is derived from lysine, and putrescine is a derivative of ornithine. Both emanate a disagreeable odour and have historically been used to train VR dogs $[16,17]$. Biogenic amines, such as cadaverine and putrescine, are not volatile and will often not be detected using conventional GC-MS analysis, although they have been detected by alternative techniques [65]. Further decomposition of these amines are required to produce volatile organic compounds (VOCs) [14,18]. For example, the process of oxidative decarboxylation is also responsible for the production of the odorous compounds dimethylamine (DMA) and trimethylamine (TMA) which are more readily detected by GC-MS [14]. Deamination, the process involving the removal of the amino terminus of the amino acid, yields nitrogenous products and ammonia, which can be used by other organisms as a source of energy as part of the nitrogen cycle [15].

Short chain alcohols, such as propanol and pentanol, and short branched alcohols, such as 2-methyl propanol, 2-methyl butanol, and 3methyl butanol, are by-products of the amino acids valine, leucine and isoleucine via the Ehrlich pathway [6,14].

Thiols, sulphides and inorganic sulphurous gases are produced from amino acids containing sulphur, as a result of desulfhydration and reaction with ROS [19,20]. For example, desulfhydralation of methionine results in methanethiol [20-22]. Subsequent oxidative reactions of methanethiol and hydrogen sulphide results in a number of disulphide compounds including the VOCs dimethyl disulphide (DMDS) produced from the oxidation of methanethiol; dimethyl trisulphide (DMTS) from the oxidation of methanethiol and hydrogen sulphide and dimethyl tetrasulphide (DMQS) [23-26]. It is these sulphur-containing compounds and inorganic gases responsible for the foul-smelling odour associated with decomposition [27]. The exact processes of oxidation resulting in the production of DMDS, DMTS and DMQS are largely unknown $[18,23]$. Under anaerobic conditions, such as underwater, these VOCs will not degrade any further; however, under aerobic conditions they will eventually oxidise to produce elemental sulphur [14].

The breakdown of aromatic amino acids such as phenylalanine, tryptophan and tyrosine will result in the production of substances such as skatole and indole [14]. Other by-products associated with the breakdown of aromatic amino acids include phenol, ethylbenzene, benzaldehyde and benzonitrile [14].

\subsection{VOCs from the decomposition of lipids}

Lipids are present within every human cell in the form of phospholipids which make up the cell membrane [14]. Adipose tissue is predominantly comprised of lipids alongside small amounts of water and proteins. The vast majority of lipids are triglycerides which consist of three fatty acids attached, via an ester linkage, to a single glycerol molecule [28]. These fatty acids may be either unsaturated, such as linoleic or palmoleic acids, or saturated, for example palmitic acid [14].

Initially, decomposition of fat is predominantly from hydrolysis of the triglyceride ester bond from the action of lipases. A high concentration volatile fatty acids (VFA), is produced [29]. Fatty acids may subsequently undergo either oxidation or hydrogenation and, under aerobic conditions, will be degraded into carbon dioxide and water [14]. The degradation of fats will result in an array of different acids including short chain acids like formic acid, acetic acid, butanoic acid and longer chain acids such as tetradecanoic acid, hexadecanoic acid and octadecanoic acid [14]. The full mechanisms of VOC production via VFA degradation are largely unknown but many different microbial breakdown pathways will result in the production of acetyl CoA and propanoyl CoA [12] which can be further broken down to produce the VOCs ethanol, acetic acid, ethanal and acetone or to propan-1-ol, propan-2-ol, and propanoic acid respectively [6].

ROS and microbial species will oxidise lipids to release a variety of volatile organic species including alkenes, alcohols, aldehydes and ketones [9,14], such as ethanol, butanol, octan-1-ol, 1-octen-3-ol, pentanal, hexanal, heptanal, nonanal and nonan-2-one [14].

Under anaerobic moist conditions, adipose tissue can saponify, producing adipocere. The chemical process of saponification occurs in conditions where the action of bacteria responsible for the usual decomposition processes is inhibited [30,31], and involves the reaction of fatty acids with sodium or potassium ions to produce insoluble salts [14]. Adipocere often gives rise to the preservation of human remains $[30,32]$.

Although there is extensive literature on the VOCs emitted from the decomposition process of buried and surface deposited human remains $[33,34]$ and pig remains using a variety of techniques [35-38], there is no known research on the chemicals produced by remains submerged in water. Although it has been proven that dogs are capable of locating submerged remains [39], the specific compounds - or combination of compounds - to which they are responding has not been ascertained [18]. There are difficulties associated with the headspace analysis of VOCs in water as this technique relies on the partition of a volatile analyte between the solution and the gas phases to reach equilibrium. Hydrophilic or polar compounds, which are readily dissolved in water, will preferentially remain in solution and therefore be at lower concentrations in the vapour phase than would be expected in the absence of liquid. However, this effect would be minimal for hydrophobic compounds with low solubilities. The volatility of any compound is directly proportional to temperature, and the headspace concentration of many VOCs would be lower in colder conditions such as those which may be experienced in a field setting. 
Table 1

Details of pigs utilised for experiments.

\begin{tabular}{llllll}
\hline Pig Number & Sex & Mass $(\mathrm{kg})$ & Length $(\mathrm{cm})$ & Location & $\begin{array}{l}\text { Trial start (trial } \\
\text { number) }\end{array}$ \\
\hline A1 & F & 6.3 & 55 & Surface & 16th March 2015 (1) \\
W1 & M & 6.0 & 52 & Submerged & 16th March 2015 (1) \\
A2 & M & 6.8 & 56 & Surface & 16th March 2015 (1) \\
W2 & M & 7.8 & 61 & Submerged & 16th March 2015 (1) \\
A3 & M & 13.6 & 77 & Surface & 9th May 2015 (2) \\
W3 & F & 8.9 & 59 & Submerged & 9th May 2015 (2) \\
\hline
\end{tabular}

\section{Materials and methods}

\subsection{Samples}

Six pig carcasses (6.0-13.6 kg) were used as human analogues and placed in $64 \mathrm{~L}$ plastic boxes (Really Useful Boxes ${ }^{\circledR}$, UK). Pigs were chosen as analogues due to their physiological similarities to humans [18,62-64]; they are the training material of choice for cadaver dogs in the UK; and no ethical permissions were required as the pigs were fallen stock, purchased post-mortem and were not slaughtered for the purposes of research [40]. Three pigs were submerged in $36 \mathrm{~L}$ of deionised water, and the remaining three were left to decompose for a maximum of 93 days in the air enclosed in the boxes, in an outdoor decomposition facility in the north of the UK (Table 1). The outdoor facility has a valid DEFRA licence for using Category 2 animals and animal-by products for research purposes.

As controls, one $35 \mathrm{~L}$ box of the same type was left empty and another filled with $18 \mathrm{~L}$ of deionised water, from which control samples were taken. Four $10 \mathrm{~mm}$ diameter holes were drilled into each box at a height of $400 \mathrm{~mm}$ to allow for insect access, air flow and sampling. Boxes were placed at least $2 \mathrm{~m}$ apart to reduce possible cross contamination of odours when sampling. Experiments were conducted over the spring and summer months, from 16th March 2015 to 17th July 2015. Ambient temperatures and the internal temperatures of the boxes were recorded for the duration of the study to allow for calculation of Accumulated Degree Days (ADD) to allow comparisons to be made between the two trials.

\subsection{Decomposition stages}

Decomposition states were recorded through photographing and contemporaneous notes on each sampling day. Stages were assigned based on an adapted version of the approach of Payne (1965) [41] and Payne and King's (1970) [42] for estimating decomposition stages of pigs in terrestrial and aquatic settings respectively (Tables 2 and 3). Modifications were made so both the terrestrial and aquatic decomposition process consisted of five stages each to allow for direct comparison. As decomposition is a continuous process, sometimes multiple stages (differential decomposition or "mosaic effect") were evident on one carcass; if this was the case, the one deemed to be the most predominant was recorded. This was in accordance with previous similar studies $[18,43]$.

\subsection{Solid phase micro extraction sampling of Volatile Organic Compounds}

30/50 $\mu \mathrm{m}$ Stableflex Polydimethysiloxane Carboxen Divinylbenzene (PDMS/CAR/DVB) SPME fibres (Supelco, Sigma Aldrich) were chosen for sampling based on previously published methods [17,44]. In order to maximise the VOC concentrations available for SPME analysis, rubber bungs were used to block the drilled holes to allow accumulation of decomposition VOCs within the headspace of the boxes for $1 \mathrm{~h}$ prior to analysis. Rubber bungs were included in the analysis of the control boxes. SPME fibres were exposed to samples in situ for $40 \mathrm{~min}$ at ambient temperatures within the boxes. One sample from each pig was
Table 2

Terrestrial decomposition stages adapted from Payne (1965) [41].

\begin{tabular}{ll}
\hline Decomposition Stage & Description and Observable Features \\
\hline Fresh (Fr) & No decompositional features evident \\
Bloat (Bl) & No discernible odour \\
& Inflation of carcass due to accumulation of gases \\
& internally. May lead to splayed limbs \\
& Greenish discolouration observed around the abdomen \\
& which spreads to other areas of carcass \\
& Purging of fluids due to increase in pressure \\
& Skin sloughing and the formation of fluid filled blisters \\
& may occur \\
& Decomposition odour may be discernible \\
& Fly oviposition evident \\
& Deflation of carcass as gases escape \\
& Wet appearance \\
Active Decay (AcD) & Strong putrid decompositional odour \\
& Maggot masses present \\
& Drying of soft tissue \\
& Exposure of skeletal elements \\
& Decrease in odour \\
Advanced Decay (AvD) & Maggots migrate away from carcass to pupate \\
& Mummification of remaining soft tissue \\
& Majority of skeletal elements exposed \\
& \\
Skeletonisation (Sk) & \\
& \\
& \\
& \\
& \\
& \\
& \\
&
\end{tabular}

Table 3

Aquatic decomposition stages adapted from Payne and King (1970) [42].

\begin{tabular}{|c|c|}
\hline Decomposition Stage & Description and Observable Features \\
\hline Fresh (Fr) & $\begin{array}{l}\text { No decompositional features evident } \\
\text { Carcass does not breach water-line } \\
\text { No discernible odour }\end{array}$ \\
\hline Early Float (EF) & $\begin{array}{l}\text { Greenish discolouration may be visible on } \\
\text { abdomen } \\
\text { Carcass breaches water-line so some flesh exposed } \\
\text { to air } \\
\text { Decomposition odour may be discernible } \\
\text { Fly oviposition evident on areas of exposed flesh }\end{array}$ \\
\hline Floating Decay (FD) & $\begin{array}{l}\text { Inflation of carcass due to accumulation of gases } \\
\text { internally. May lead to splayed limbs } \\
\text { Greenish discolouration observed around the } \\
\text { abdomen which spreads to other areas of carcass } \\
\text { Skin sloughing and the formation of fluid filled } \\
\text { blisters may occur } \\
\text { Purging of fluids due to increase in pressure } \\
\text { Strong putrid decompositional odour } \\
\text { Maggot masses apparent on exposed areas of flesh }\end{array}$ \\
\hline $\begin{array}{l}\text { Advanced Deterioration } \\
\quad \text { (AD) }\end{array}$ & $\begin{array}{l}\text { Deflation of carcass as gases escape } \\
\text { Carcass begins to disintegrate and sink } \\
\text { Carcass may blacken in areas } \\
\text { Exposed soft tissue begins to dry and harden } \\
\text { Reduction in decompositional odour } \\
\text { Migration of maggots } \\
\text { Some exposure of skeletal elements }\end{array}$ \\
\hline Sunken Remains (SR) & $\begin{array}{l}\text { Carcass sinks below water line } \\
\text { Some dried/mummified skin may remain floating } \\
\text { on surface }\end{array}$ \\
\hline
\end{tabular}

taken per day. SPME fibres were analysed within $10 \mathrm{~min}$ of exposure to the VOCs. VOC collection was carried out at regular intervals of every 3 days, until the pigs reached the advanced decay or advanced deterioration stage, when the abundance of VOCs began to reduce. Thereafter, sampling was conducted on a weekly basis. Sampling was carried out over a period of 123 days. An internal standard was not used for this study as the focus was qualitative rather than quantitative analysis. SPME fibres were cleaned between samples through thermal desorption at $250^{\circ} \mathrm{C}$ for $1 \mathrm{~h}$. Cleaned fibres were analysed prior to any sampling event.

\subsection{Gas Chromatography Mass Spectrometry analysis}

GCMS analysis was carried out with a GC Agilent $6890 \mathrm{~N}$ with an 
Agilent 5975 Inert XL mass selective detector (EI source) and a $30 \mathrm{~m} \times 250 \mu \mathrm{m} \times 0.25 \mu \mathrm{m}$ HP-5MScolumn (5\% diphenyl/ 95\% dimethylpolysiloxane, Agilent Technologies). A $0.75 \mathrm{~mm}$ ID SPME injection port liner was operated in splitless mode at $270{ }^{\circ} \mathrm{C}$. Helium carrier gas was set to a $1 \mathrm{~mL} / \mathrm{min}$ flow rate. Initial temperature of $35^{\circ} \mathrm{C}$ held for $4 \mathrm{~min}$, ramped to $120^{\circ} \mathrm{C}$ at a rate of $20^{\circ} \mathrm{C} / \mathrm{min}$ then ramped to $150{ }^{\circ} \mathrm{C}$ at a rate of $10^{\circ} \mathrm{C} / \mathrm{min}$ with a final ramp to $260^{\circ} \mathrm{C}$ at a rate of $20{ }^{\circ} \mathrm{C} / \mathrm{min}$, holding the final temperature for $2 \mathrm{~min}$. The mass range monitored was 20-400 amu.

\subsection{Data processing}

Data was analysed using Chemstation software (Agilent Technologies), and the National Institute of Standards and Technology library(NIST 05) was used to compare and match mass spectra to identify VOCs. Peaks were manually integrated. Peaks identified were given a quality score by the NIST software out of 100 . All those with a quality score $<70$ were ignored. Peaks which did not meet a 3:1 signal to noise ratio were also discounted. All compounds known to be artefacts of the column, sampling or detection process were ignored. This was done by comparing samples data to the controls and blanks. Any VOCs which were also found in the blanks or controls were ignored. The average peak areas for the ten most abundant VOCs detected from the surface-deposited porcine cadavers $(n=3)$ and the water-submerged cadavers $(n=3)$ were calculated, to show their relative abundance.

The statistical analysis package $\mathrm{R}$ version 3.2.2 ( $\mathrm{R}$ Foundation for Statistical Computing2015) was used to process the data gathered using Principal Co-ordinate Analysis (PCoA). PCoA was used to visualise similarities with the data collected, by reducing dimensionality through simplifying the input variables (i.e. the chemical classes detected and the frequency they were observed). These similarities are presented by means of PCoA score biplot. Points which are clustered close together exhibit high degrees of similarity whereas points which are further away from each other exhibit low degrees of similarity. The results that are presented are shown using the first two principal co-ordinates as they displayed the most of the variation between samples within the data set.

\section{Results}

\subsection{Identification of VOCs}

A total number of seventy-four VOCs were identified (Table 4). This included VOCs from a variety of different chemical classes; carboxylic acids, alcohols, aromatics, aldehydes, ketones, hydrocarbons, esters, ethers, nitrogen compounds and sulphur compounds. Forty-one VOCs were detected in the headspace of the submerged pigs with seventy detected in the headspace of the surface-deposited pigs.

Twelve of the VOCs detected have not been previously reported in the literature. These VOCs were identified from comparisons to the NIST mass spectral library. Further confidence in identification could have been achieved if the reference material was available. Thirty-two compounds (43\%) were found only in the surface-deposition environment. All of these compounds only appeared in low frequencies. Four compounds ( $5 \%$ of all the VOCs detected) were found only within the submerged environment. These included: 2,6- bis (1,1-dimethylethyl)4-(1-methylpropyl) phenol, 4methylpentan-1-ol, butanal and hexyl hexanoate. All of these compounds also only appeared at low frequencies. It should be noted that 2,6- bis (1,1-dimethylethyl)-4-(1-methylpropyl) phenol may have been produced by the plastic boxes in which the pigs were placed.

VOC occurrence was calculated by dividing the number of times a VOC was observed during a decomposition stage by the total number of sampling days that stage was present. This was calculated per pig and then averaged, to produce the results seen in Table 5 .

Through averaging, the most prevalent VOCs identified consistently for each pig in both environments can be easily observed with any anomalies reduced in significance. Each colour represents the frequency of each VOC at each stage of decomposition in each environment.

\subsection{Surface-deposition}

Fig. 1 shows the average peak areas for the ten most abundant VOCs detected from the surface-deposited porcine cadavers against the postmortem interval. This shows how the relative abundance of the 10 most abundant VOCs peaks between 27 and 55 days, which coincides with the active decay stage and the advanced decay stage. The diversity of the VOCs emitted increases in this period as well. The VOC profiles of the fresh and skeletonised stages show most similarity.

The VOC signatures detected over the five stages of decomposition for the three surface-deposited pigs were analysed using a Principal Coordinate Analysis (PCoA) (Figs. 3 and 4). This approach was chosen over the more widely used Principal Components Analysis (PCA) due to the type of data collected. Only qualitative presence or absence data was collected, which is not suitable for PCA. Each pig had five different stages attributed to it: (1) fresh, (2) bloat, (3) active decay, (4) advanced decay, and (5) skeletonisation.

Observing Fig. 3, there is a clear distinction between the fresh stage to the bloat, active and advanced decay stages. The chemical signatures become more complex as the process of decomposition occurs, and the chemicals detected are found in higher abundances (Fig. 1) later on in the process. However, there are distinct similarities in the VOC profile identified during the fresh and skeletonisation stages.

Using this PCoA approach, it is possible to clearly distinguish between three broad groups of decomposition, namely fresh, decay (including bloat, active and advanced), and skeletonisation. With more data, it could be possible to differentiate between the stages of individual stages of decay, including the bloat, active decay, and advanced decay stages. However, overlaps between these three groups are still visible.

All but nitrogen and sulphur chemical classes have positive loads along the horizontal axis with all but two chemical classes having negative loadings on the vertical axis. Cyclic hydrocarbons and ethers are on the opposite scale to the nitrogen and sulphur chemical classes. This indicates that cyclic hydrocarbons and ethers are not correlated with nitrogen-containing or sulphur-containing chemical classes, and that they would not be found together. The fresh stage of decomposition is most closely related to cyclic hydrocarbons and ethers. The bloat and active stages have a stronger correlation with nitrogen and sulphur containing chemicals. The advanced decay stage is strongly associated with acids, alcohols, non-cyclic hydrocarbons and ketones.

\subsection{Submerged remains}

Fig. 2 shows the average peak areas for the 10 most abundant VOCs detected from all the submerged porcine cadavers against the postmortem interval. The odour profile for submerged remains is more complicated than that of the surface-deposited porcine cadavers. The highest peak areas occur between 15 and 47 days post-mortem, in the early float and floating decay stage (1-Butanol, average peak area $=68,283$; Indole, average peak area $=54,475)$. Again, the earliest stage (fresh) and latest stage (sunken remains) are characterised by the fewest VOCs being emitted and at the lowest relative abundances.

The results from the PCoA (Fig. 5) show that there is a clear distinction between the floating stages and the advanced stage of decay. It is hypothesised that any positive value along the first principal coordinate will indicate that the specimen is undergoing either the floating or advanced stages of decay but is more likely to be in the advanced stage. As seen previously in the surface-deposition experiment, the final stage where the remains are sunken or skeletonised is most similar to the floating decay stage. Aquatic decomposition can be seen as either a cycle or a U-turn in terms of the presence of VOCs, as 
Table 4

VOCs detected and their frequency of detection in headspace samples over the duration of the experiment, with existing literature corroborating VOC detection. Air: Low $\leq 20 \%$; Medium $=20-40 \%$; High $\geq 40 \%$. Water: Low $\leq 10 \%$; Medium $=10-20 \%$; High $\geq 20 \%$.

\begin{tabular}{|c|c|c|c|c|}
\hline Compound class & VOC detected & $\begin{array}{l}\text { Frequency Detected } \\
\text { (Surface-deposited) }\end{array}$ & $\begin{array}{l}\text { Frequency Detected } \\
\text { (Sub-merged) }\end{array}$ & $\begin{array}{l}\text { Literature reference where VOC previously detected (associated } \\
\text { with mammalian decomposition) }\end{array}$ \\
\hline \multirow[t]{23}{*}{ Carboxylic Acids } & 2-methyl butanoic acid & High & Medium & {$[18,35,38,40,45,46]$} \\
\hline & 2-methyl propanoic acid & Medium & Low & {$[18,35,38,40,45,46]$} \\
\hline & 3-methyl butanoic acid & High & Medium & {$[7,18,35,38,40,46]$} \\
\hline & 4-hydroxy benzenepropanoic acid & Low & - & Not referenced in the literature \\
\hline & 4-methyl pentanoic acid & Medium & Medium & {$[35,38]$} \\
\hline & Acetic (ethanoic) acid & Medium & Low & {$[7,17,18,36,40,46,47]$} \\
\hline & Benzeneacetic acid & Low & Low & {$[48]$} \\
\hline & Benzenecarboxylic acid & Low & - & Not referenced in the literature \\
\hline & Benzenepropanoic acid & Low & Low & {$[48]$} \\
\hline & Butanoic Acid & High & Medium & {$[7,18,35,38,40,44-47]$} \\
\hline & Decanoic Acid & Low & - & Not referenced in the literature \\
\hline & Dodecanoic Acid & Low & - & Not referenced in the literature \\
\hline & Heptadecanoic Acid & Low & - & Not referenced in the literature \\
\hline & Hexadecanoic (Palmitic) Acid & Low & Low & {$[38]$} \\
\hline & Hexanoic (Caproic) Acid & Low & - & {$[17,18,35,38,44,46]$} \\
\hline & Nonanoic Acid & Low & - & {$[35]$} \\
\hline & Octadecanoic Acid & Low & Low & Not referenced in the literature \\
\hline & Octadecenoic (Oleic) Acid & Low & - & Not referenced in the literature \\
\hline & Octanoic Acid & Low & - & {$[17,35,38]$} \\
\hline & Pentanoic (Valeric) Acid & Low & Low & {$[18,35,38,40,44,46]$} \\
\hline & Pentadecanoic Acid & Low & - & Not referenced in the literature \\
\hline & Propanoic Acid & Low & Low & {$[18,35,38,40,44,46,47]$} \\
\hline & Tetradecanoic acid & Low & Low & Not referenced in the literature \\
\hline \multirow[t]{12}{*}{ Alcohols } & $\begin{array}{l}\text { 2,6-bis (1,1-dimethylethyl)-4- } \\
\text { (1methylpropyl) phenol }\end{array}$ & Low & - & Not referenced in the literature \\
\hline & $\begin{array}{l}\text { 2,6-bis (1,10dimethylethyl)-4-(1- } \\
\text { oxopropyl) phenol }\end{array}$ & - & Low & Not referenced in the literature \\
\hline & 2-methyl butan-1-ol & Low & Low & {$[47]$} \\
\hline & 3-methyl butan-1-ol & Low & Low & {$[7,35,40,46,47,49,50]$} \\
\hline & 4-methyl pentan-1-ol & - & Low & {$[38]$} \\
\hline & 4-methyl phenol (p-cresol) & Medium & High & {$[35,38,40,46,50,51]$} \\
\hline & Butan-1-ol & Medium & High & {$[18,33,35,36,38,40,45-47,50]$} \\
\hline & Ethanol & Low & - & {$[33,35,38,40,46,51,52]$} \\
\hline & Pentan-1-ol & Low & Low & {$[18,33,35,38,40,44-46]$} \\
\hline & Phenol & High & High & {$[17,18,35-37,40,46,47,50-52]$} \\
\hline & $\begin{array}{l}\text { Phenyl ethyl alcohol (2- } \\
\text { phenylethanol) }\end{array}$ & Low & Low & {$[35,40,46]$} \\
\hline & Propan-2-ol (Isopropyl alcohol) & Low & - & {$[40,45,46,49,51,52]$} \\
\hline \multirow[t]{5}{*}{ Aldehydes } & Benzaldehyde & Low & - & {$[17,18,29,35-38,44,46,47]$} \\
\hline & Butanal & - & Low & {$[35,36,46]$} \\
\hline & Heptanal & Low & - & {$[7,18,35,38,44,46,47,50]$} \\
\hline & Hexanal & Low & - & {$[18,33,38,40,44,46,47]$} \\
\hline & Nonanal & Low & - & {$[7,17,29,38,40,44-46,50,53]$} \\
\hline \multirow[t]{8}{*}{ Esters } & 2-methyl butyl butanoate & Low & Low & {$[33,35,38,40,45]$} \\
\hline & $\begin{array}{l}\text { 3-(4-methoxyphenyl)- } 2 \text { ethylhexyl } \\
\text { ester }\end{array}$ & Low & - & Not referenced in the literature \\
\hline & 3-methyl butyl butanoate & Low & Low & {$[35,38,40]$} \\
\hline & Butyl acetate (ethanoate) & Low & Low & {$[35,36,45-47]$} \\
\hline & Butyl butanoate & Low & Low & {$[35,38,40,44-46]$} \\
\hline & Butyl hexanoate & Low & Low & {$[38]$} \\
\hline & Ethyl butanoate & Low & Low & {$[33,40,44-47,49]$} \\
\hline & Hexyl hexanoate & - & Low & [44] \\
\hline Ethers & Tetrahydrofuran & Low & - & [49] \\
\hline \multirow{4}{*}{ Ketones } & Acetone & Low & Low & {$[35,36,45]$} \\
\hline & Acetophenone (1-Phenylethanone) & Low & Low & {$[35-38,40,46,50,51]$} \\
\hline & Decan-2-one & Low & - & {$[18,46,51,52]$} \\
\hline & Pentadecan-2-one & Low & - & Not referenced in the literature \\
\hline \multirow{2}{*}{$\begin{array}{l}\text { Hydrocarbons } \\
\text { (Aromatic/Cyclic) }\end{array}$} & p-xylene & Low & - & {$[29,33,44,51,53]$} \\
\hline & Toluene & Low & - & {$[17,29,33,36,38,44,46,47,51,53]$} \\
\hline \multirow{5}{*}{$\begin{array}{l}\text { Hydrocarbons (Non- } \\
\text { cyclic) }\end{array}$} & Heptadec-8-ene & Low & - & {$[40,46]$} \\
\hline & Hexadecane & Low & Low & {$[17,38,47]$} \\
\hline & Nonadecane & Low & Low & {$[46]$} \\
\hline & Pentadecane & Low & Low & {$[17,36,40,46,47]$} \\
\hline & Tetradecane & Low & - & {$[17,36,38,46]$} \\
\hline
\end{tabular}


Table 4 (continued)

\begin{tabular}{|c|c|c|c|c|}
\hline Compound class & VOC detected & $\begin{array}{l}\text { Frequency Detected } \\
\text { (Surface-deposited) }\end{array}$ & $\begin{array}{l}\text { Frequency Detected } \\
\text { (Sub-merged) }\end{array}$ & $\begin{array}{l}\text { Literature reference where VOC previously detected (associated } \\
\text { with mammalian decomposition) }\end{array}$ \\
\hline Nitrogen-containing & 2-methyl propanamide & Low & - & {$[38]$} \\
\hline \multirow[t]{9}{*}{ Compounds } & 2-Piperidinone & Medium & Low & {$[35,37,38,40,46,52]$} \\
\hline & 3-methyl butanamide & Low & - & {$[35,38,46]$} \\
\hline & 3-methyl $1 \mathrm{H}$ indole (skatole) & Low & - & {$[18,38,47]$} \\
\hline & Butanamide & Low & - & {$[35,38,46]$} \\
\hline & Indole & High & High & {$[18,35,36,38,40,44,46,47,50,52]$} \\
\hline & Quinoline & Low & - & {$[38]$} \\
\hline & Tetramethylpyrazine & Low & - & {$[38,47]$} \\
\hline & Trimethylamine & Medium & High & {$[18,35,36,38,40]$} \\
\hline & Trimethylpyrazine & Low & - & [38] \\
\hline Sulphur Containing & Dimethyl disulphide & High & Medium & {$[18,29,33,36-38,40,44,46,47,49-53]$} \\
\hline \multirow[t]{3}{*}{ Compounds } & Dimethyl trisulphide & High & High & {$[17,18,29,33,36-38,40,46,47,49-53]$} \\
\hline & Dimethyl tetrasulphide & Low & Low & {$[18,36,37,46,47]$} \\
\hline & Methanethiol & Low & Low & {$[35,36,46,47,49]$} \\
\hline
\end{tabular}

similar VOCs are present and absent in the third and last stages of decomposition, however, more data would be needed to fully investigate this inference.

Cyclic hydrocarbons and nitrogen containing compounds did not have any effect on the PCoA loadings (Fig. 6). No VOCs were detected in the fresh stage of decomposition and only one, dimethyl trisulphide, in the early float stage. This can be seen in Fig. 5 where both stages overlap. Therefore, all chemical groups, with the exception of cyclic hydrocarbons and nitrogen-containing compounds, are loaded positively along the horizontal axis as they are distinct from the first two stages of decay (Fig. 6).

Along the vertical axis (Fig. 6), alcohols, sulphur-containing and nitrogen-containing compounds are not correlated with esters, ketones, aldehydes, non-cyclic hydrocarbons and acids. Alcohols, sulphur-containing and nitrogen-containing compounds are found in both the floating decay and advanced decay stages of submerged decomposition, but are more closely associated with the advanced decay stage. However, there is less correlation found with chemical classes and decomposition stage for the submerged pigs in comparison to the surface deposited pigs. This is likely due to the lower numbers of VOCs detected in the headspace of the submerged pigs.

\section{Discussion}

The VOCs detected were mostly consistent with the published literature discussing scent profiles of decomposing pigs [35,37,38,49]. All chemical classes were represented, with the exception of halogenated compounds.

The pigs deposited in the later experiment (9th May 2015) produced a greater number and diversity of VOCs at all stages of decomposition, with the exception of the fresh stage for the surface-deposited pigs. This was despite the duration of the stages being shorter than those seen with the deposition which started in March 2015. This is probably due to the lower temperatures to which the pigs in the first deposition were exposed, and is consistent with the study carried out over two different months by Forbes et al. (2014) [40]. Additionally, the larger mass of the pigs in the second trial is likely to have contributed to larger concentrations of VOCs, facilitating their detection, and subsequent identification, by GC-MS. However, this cannot be confirmed as no quantitation of VOCs was attempted in this study. Alternatively, the differences in VOCs could be due to the different sources from where the pigs were obtained [36]. However, differences seen in both the rates of decomposition and the VOCs produced between the pigs of the first trial which suggests even if all of the pigs were sourced from the same place, natural individual variation which cannot be controlled for has a large effect on decomposition and thus the VOCs produced.

\subsection{Contribution of insects to VOC profile}

Insect recolonisation of the both the submerged and surface-deposited pigs was observed, and corresponded to a second spike in the appearance of VOCs at Day 28. This has also been reported in the literature in cases of terrestrial decomposition [46,48], however, no mention of this phenomenon could be found in relation to submerged pigs. This event could complicate the potential use of VOCs for the estimation of post-mortem interval. The temperature and weather could have also had a role in this second spike of VOCs. A number of studies have illustrated the role of different cadaveric VOCs in attracting necrophagous insects to cadavers [7,50,54-57]. It is possible that a secondary release of VOCs contributed to the attraction, oviposition and subsequent second colonisation of insects seen in this study. Frederickx and colleagues (2012) [54] also presented evidence that maggots will contribute to a VOC profile, showing over 92 VOCs associated with the larvae and pupae of the $C$. vicina species alone. Of these 92 volatiles, 16 were detected in the present study including: methanethiol, ethanol, acetic acid, 3-methyl butan-1-ol, 2-methyl butan-1-ol, hexanal, p-xylene, benzaldehyde, phenol, nonanal, indole, butyl butanoate, tetradecanoic acid, pentdecanoic acid, hexadecanoic acid and octadecanoic acid. Of these, p-xylene, nonanal, tetradecanoic acid, pentadecanoic acid, hexadecanoic acid and octadecanoic acid are associated with larval stages of the $C$. vicina life cycle and would help to explain why these compounds were detected during the early stages of decomposition (fresh and bloat). Phenol and indole are also associated with the larval stages and were associated with both the active decay, when maggot masses were present, and the advanced decay stages, when maggots reappeared. The remainder of the VOCs such as methanethiol, ethanol, acetic acid, 3-methyl butan-1-ol, 2-methyl butan-1-ol, are associated with the pupae of $C$. vicina, which would explain their appearances in the later stages of decay, as maggots began to pupate. Therefore, it is also possible that the second spike of VOCs observed was due to the production of VOCs from the second set of maggots, or it could be a combination of these factors. Further investigation of cadaveric VOCs without the presence of insects would be required to separate the two individual profiles and may also help in understanding the biochemical origin of decomposition VOCs. However, in real-life scenarios, it is unlikely that a body found on land will not be in association with insects unless measures have been taken to prevent insect colonisation [58]. Despite this, for cadaver dog training purposes, it is important to isolate the two VOC profiles; those from a human body and those from insects, in order to reduce the possibility of dogs indicating on simply the presence of maggots (as these VOCs may swamp or mask the VOCs produced by a human body). This could also be a confounding factor when search areas may include animal remains colonised by necrophagous insects.

The absence or presence of insects seemed to affect the VOC profile 
Table 5

Average Occurrence of VOCs per chemical class for both surface-deposited and submerged environments. Surface decomposition stages: $\mathrm{Fr}=\mathrm{Fresh}, \mathrm{Bl}=\mathrm{Bloat}$, $\mathrm{AcD}=$ Active Decay, $\mathrm{AvD}=$ Advanced Decay, $\mathrm{Sk}=$ Skeletonised. Submerged decomposition stages: Fr $=$ Fresh, EF $=$ Early Float, FD $=$ Floating Decay, $\mathrm{AD}=$ Advanced Deterioration, $\mathrm{SR}=$ Sunken Remains

\begin{tabular}{|c|c|c|c|c|c|c|c|c|c|c|c|}
\hline \multirow{2}{*}{ Chemical Class } & \multirow{2}{*}{ Compound } & \multicolumn{5}{|c|}{ Surface-deposited } & \multicolumn{5}{|c|}{ Submerged } \\
\hline & & Fresh & Bloat & AcD & AvD & Sk & Fr & EF & FD & AD & SR \\
\hline \multirow[t]{23}{*}{ Acids } & 2-methyl Butanoic Acid & 0.00 & 0.14 & 0.81 & 0.86 & 1.00 & 0.00 & 0.00 & 0.08 & 0.40 & 0.20 \\
\hline & 2 methyl Propanoic Acid & 0.00 & 0.14 & 0.50 & 0.38 & 1.00 & 0.00 & 0.00 & 0.00 & 0.22 & 0.00 \\
\hline & 3-methyl Butanoic Acid & 0.00 & 0.14 & 0.81 & 0.89 & 1.00 & 0.00 & 0.00 & 0.08 & 0.36 & 0.00 \\
\hline & 4-hydroxy Benzenepropanoic Acid & 0.00 & 0.00 & 0.00 & 0.03 & 0.00 & 0.00 & 0.00 & 0.00 & 0.00 & 0.00 \\
\hline & 4-methyl Pentanoic Acid & 0.00 & 0.14 & 0.00 & 0.54 & 1.00 & 0.00 & 0.00 & 0.00 & 0.22 & 0.20 \\
\hline & Acetic (Ethanoic) Acid & 0.00 & 0.14 & 0.38 & 0.41 & 0.75 & 0.00 & 0.00 & 0.00 & 0.04 & 0.00 \\
\hline & Benzeneacetic acid & 0.00 & 0.00 & 0.00 & 0.03 & 0.50 & 0.00 & 0.00 & 0.00 & 0.02 & 0.00 \\
\hline & Benzenecarboxylic acid & 0.00 & 0.00 & 0.00 & 0.03 & 0.50 & 0.00 & 0.00 & 0.00 & 0.00 & 0.00 \\
\hline & Benzenepropanoic acid & 0.00 & 0.00 & 0.00 & 0.03 & 0.50 & 0.00 & 0.00 & 0.00 & 0.02 & 0.00 \\
\hline & Butanoic Acid & 0.00 & 0.50 & 0.81 & 0.89 & 1.00 & 0.00 & 0.00 & 0.15 & 0.44 & 0.20 \\
\hline & Decanoic Acid & 0.00 & 0.00 & 0.00 & 0.03 & 0.00 & 0.00 & 0.00 & 0.00 & 0.00 & 0.00 \\
\hline & Dodecanoic Acid & 0.13 & 0.00 & 0.00 & 0.03 & 0.50 & 0.00 & 0.00 & 0.00 & 0.00 & 0.00 \\
\hline & Heptadecanoic Acid & 0.00 & 0.00 & 0.00 & 0.00 & 0.25 & 0.00 & 0.00 & 0.00 & 0.00 & 0.00 \\
\hline & Hexadecanoic Acid & 0.25 & 0.07 & 0.06 & 0.05 & 0.75 & 0.00 & 0.00 & 0.00 & 0.02 & 0.20 \\
\hline & Hexanoic Acid & 0.00 & 0.00 & 0.00 & 0.03 & 0.00 & 0.00 & 0.00 & 0.00 & 0.00 & 0.00 \\
\hline & Nonanoic Acid & 0.00 & 0.00 & 0.00 & 0.00 & 0.25 & 0.00 & 0.00 & 0.00 & 0.00 & 0.00 \\
\hline & Pentadecanoic Acid & 0.13 & 0.00 & 0.00 & 0.00 & 0.50 & 0.00 & 0.00 & 0.00 & 0.00 & 0.00 \\
\hline & Pentanoic Acid & 0.00 & 0.00 & 0.06 & 0.19 & 1.00 & 0.00 & 0.00 & 0.00 & 0.11 & 0.20 \\
\hline & Propanoic Acid & 0.00 & 0.00 & 0.31 & 0.16 & 0.25 & 0.00 & 0.00 & 0.00 & 0.02 & 0.00 \\
\hline & Octadecanoic Acid & 0.13 & 0.00 & 0.06 & 0.03 & 0.75 & 0.00 & 0.00 & 0.00 & 0.00 & 0.20 \\
\hline & Octadecenoic (Oleic) Acid & 0.00 & 0.07 & 0.00 & 0.00 & 0.00 & 0.00 & 0.00 & 0.00 & 0.00 & 0.00 \\
\hline & Octanoic Acid & 0.00 & 0.00 & 0.00 & 0.00 & 0.25 & 0.00 & 0.00 & 0.00 & 0.00 & 0.00 \\
\hline & Tetradecanoic acid & 0.13 & 0.00 & 0.06 & 0.05 & 0.75 & 0.00 & 0.00 & 0.00 & 0.07 & 0.00 \\
\hline Alcohols & 2,6-bis (1,1-dimethylethyl)-4-(1methylpropyl) phenol & 0.13 & 0.00 & 0.00 & 0.00 & 0.00 & 0.00 & 0.00 & 0.00 & 0.00 & 0.00 \\
\hline & 2,6 -bis $(1,10$ dimethylethyl)-4-(1-oxopropyl) phenol & 0.00 & 0.00 & 0.00 & 0.00 & 0.00 & 0.00 & 0.00 & 0.00 & 0.00 & 0.20 \\
\hline & 2-methyl butan-1-ol & 0.00 & 0.07 & 0.06 & 0.05 & 0.00 & 0.00 & 0.00 & 0.00 & 0.02 & 0.00 \\
\hline & 3-methyl Butan-1-ol & 0.00 & 0.14 & 0.13 & 0.05 & 0.00 & 0.00 & 0.00 & 0.15 & 0.04 & 0.00 \\
\hline & 4-methyl pentan-1-ol & 0.00 & 0.00 & 0.00 & 0.00 & 0.00 & 0.00 & 0.00 & 0.08 & 0.00 & 0.00 \\
\hline & 4-methyl phenol & 0.00 & 0.07 & 0.25 & 0.24 & 0.50 & 0.00 & 0.00 & 0.15 & 0.33 & 0.80 \\
\hline & Butan-1-ol & 0.00 & 0.43 & 0.63 & 0.05 & 0.00 & 0.00 & 0.00 & 0.69 & 0.27 & 0.00 \\
\hline & Ethanol & 0.25 & 0.07 & 0.00 & 0.00 & 0.00 & 0.00 & 0.00 & 0.00 & 0.00 & 0.00 \\
\hline & Pentan-1-ol & 0.00 & 0.07 & 0.19 & 0.03 & 0.00 & 0.00 & 0.00 & 0.00 & 0.02 & 0.00 \\
\hline & Phenol & 0.00 & 0.36 & 0.69 & 0.78 & 1.00 & 0.00 & 0.00 & 0.15 & 0.47 & 0.80 \\
\hline & Phenyl ethyl alcohol & 0.00 & 0.00 & 0.00 & 0.05 & 0.00 & 0.00 & 0.00 & 0.00 & 0.07 & 0.00 \\
\hline & Propan-2-ol (Isopropyl alcohol) & 0.13 & 0.07 & 0.00 & 0.00 & 0.00 & 0.00 & 0.00 & 0.00 & 0.00 & 0.00 \\
\hline Aldehydes & Benzaldehyde & 0.00 & 0.00 & 0.06 & 0.11 & 0.00 & 0.00 & 0.00 & 0.00 & 0.00 & 0.00 \\
\hline & Butanal & 0.00 & 0.00 & 0.00 & 0.00 & 0.00 & 0.00 & 0.00 & 0.00 & 0.02 & 0.00 \\
\hline & Hexanal & 0.38 & 0.00 & 0.06 & 0.08 & 0.00 & 0.00 & 0.00 & 0.00 & 0.00 & 0.00 \\
\hline & Heptanal & 0.00 & 0.00 & 0.06 & 0.05 & 0.00 & 0.00 & 0.00 & 0.00 & 0.00 & 0.00 \\
\hline & Nonanal & 0.13 & 0.00 & 0.00 & 0.00 & 0.00 & 0.00 & 0.00 & 0.00 & 0.00 & 0.00 \\
\hline Esters & 2-methyl butyl butanoate & 0.00 & 0.00 & 0.00 & 0.03 & 0.00 & 0.00 & 0.00 & 0.00 & 0.09 & 0.00 \\
\hline & 3-(4-methoxyphenyl)- 2 ethylhexyl ester & 0.13 & 0.00 & 0.00 & 0.00 & 0.00 & 0.00 & 0.00 & 0.00 & 0.00 & 0.00 \\
\hline & 3-methyl butyl butanoate & 0.00 & 0.00 & 0.06 & 0.03 & 0.00 & 0.00 & 0.00 & 0.00 & 0.09 & 0.00 \\
\hline & Butyl acetate & 0.00 & 0.00 & 0.00 & 0.03 & 0.00 & 0.00 & 0.00 & 0.15 & 0.00 & 0.00 \\
\hline & Butyl butanoate & 0.00 & 0.14 & 0.13 & 0.03 & 0.00 & 0.00 & 0.00 & 0.08 & 0.09 & 0.00 \\
\hline & Butyl hexanoate & 0.00 & 0.07 & 0.06 & 0.03 & 0.00 & 0.00 & 0.00 & 0.00 & 0.04 & 0.00 \\
\hline & Ethyl butanoate & 0.00 & 0.00 & 0.00 & 0.00 & 0.00 & 0.00 & 0.00 & 0.00 & 0.02 & 0.00 \\
\hline & Hexyl hexanoate & 0.00 & 0.00 & 0.00 & 0.00 & 0.00 & 0.00 & 0.00 & 0.00 & 0.02 & 0.00 \\
\hline Ethers & Tetrahydrofuran & 0.13 & 0.00 & 0.00 & 0.00 & 0.00 & 0.00 & 0.00 & 0.00 & 0.00 & 0.00 \\
\hline Ketones & Acetone & 0.00 & 0.00 & 0.00 & 0.03 & 0.00 & 0.00 & 0.00 & 0.08 & 0.04 & 0.00 \\
\hline & Acetophenone & 0.00 & 0.00 & 0.00 & 0.22 & 0.00 & 0.00 & 0.00 & 0.00 & 0.02 & 0.00 \\
\hline & Decan-2-one & 0.00 & 0.00 & 0.00 & 0.05 & 0.00 & 0.00 & 0.00 & 0.00 & 0.00 & 0.00 \\
\hline & Pentadecan-2-one & 0.00 & 0.00 & 0.00 & 0.03 & 0.00 & 0.00 & 0.00 & 0.00 & 0.00 & 0.00 \\
\hline Hydrocarbons & p-xylene & 0.13 & 0.00 & 0.00 & 0.00 & 0.00 & 0.00 & 0.00 & 0.00 & 0.00 & 0.00 \\
\hline & Toluene & 0.25 & 0.00 & 0.00 & 0.00 & 0.00 & 0.00 & 0.00 & 0.00 & 0.00 & 0.00 \\
\hline & Heptadec-8-ene & 0.00 & 0.00 & 0.00 & 0.00 & 0.25 & 0.00 & 0.00 & 0.00 & 0.00 & 0.00 \\
\hline & Hexadecane & 0.00 & 0.00 & 0.00 & 0.03 & 0.00 & 0.00 & 0.00 & 0.00 & 0.02 & 0.20 \\
\hline & Nonadecane & 0.00 & 0.00 & 0.00 & 0.03 & 0.00 & 0.00 & 0.00 & 0.00 & 0.02 & 0.00 \\
\hline & Pentadecane & 0.00 & 0.07 & 0.00 & 0.16 & 0.00 & 0.00 & 0.00 & 0.00 & 0.02 & 0.00 \\
\hline & Tetradecane & 0.00 & 0.00 & 0.00 & 0.00 & 0.25 & 0.00 & 0.00 & 0.00 & 0.00 & 0.00 \\
\hline N Compounds & 2-methyl propanamide & 0.00 & 0.00 & 0.06 & 0.11 & 0.50 & 0.00 & 0.00 & 0.00 & 0.00 & 0.00 \\
\hline & 3-methyl butanamide & 0.00 & 0.00 & 0.00 & 0.05 & 0.00 & 0.00 & 0.00 & 0.00 & 0.00 & 0.00 \\
\hline & 3-methyl $1 \mathrm{H}$ indole, & 0.00 & 0.00 & 0.00 & 0.03 & 0.00 & 0.00 & 0.00 & 0.00 & 0.00 & 0.00 \\
\hline & 2-Piperidinone & 0.00 & 0.00 & 0.13 & 0.30 & 1.00 & 0.00 & 0.00 & 0.00 & 0.02 & 0.00 \\
\hline & Butanamide & 0.00 & 0.00 & 0.00 & 0.03 & 0.00 & 0.00 & 0.00 & 0.00 & 0.00 & 0.00 \\
\hline & Indole & 0.00 & 0.36 & 0.63 & 0.73 & 1.00 & 0.00 & 0.00 & 0.15 & 0.53 & 0.60 \\
\hline & Quinoline & 0.00 & 0.00 & 0.06 & 0.03 & 0.75 & 0.00 & 0.00 & 0.00 & 0.00 & 0.00 \\
\hline & Tetramethyl pyrazine & 0.00 & 0.00 & 0.00 & 0.03 & 0.00 & 0.00 & 0.00 & 0.00 & 0.00 & 0.00 \\
\hline & Trimethylamine & 0.00 & 0.50 & 0.75 & 0.19 & 0.00 & 0.00 & 0.00 & 0.62 & 0.51 & 0.00 \\
\hline & Trimethylpyrazine & 0.00 & 0.00 & 0.00 & 0.03 & 0.00 & 0.00 & 0.00 & 0.00 & 0.00 & 0.00 \\
\hline S Compounds & Dimethyl Disulphide & 0.00 & 0.50 & 0.94 & 0.24 & 0.00 & 0.00 & 0.00 & 0.31 & 0.38 & 0.00 \\
\hline & Dimethyl Trisulphide & 0.00 & 0.64 & 0.88 & 0.41 & 0.25 & 0.00 & 0.18 & 0.38 & 0.47 & 0.40 \\
\hline & Dimethyl Tetrasulphide & 0.00 & 0.14 & 0.31 & 0.05 & 0.00 & 0.00 & 0.00 & 0.08 & 0.04 & 0.00 \\
\hline & Methanethiol & 0.00 & 0.07 & 0.19 & 0.00 & 0.00 & 0.00 & 0.00 & 0.08 & 0.04 & 0.00 \\
\hline
\end{tabular}

KEY: $\quad$ Fractional Occurrence (Low to High) 


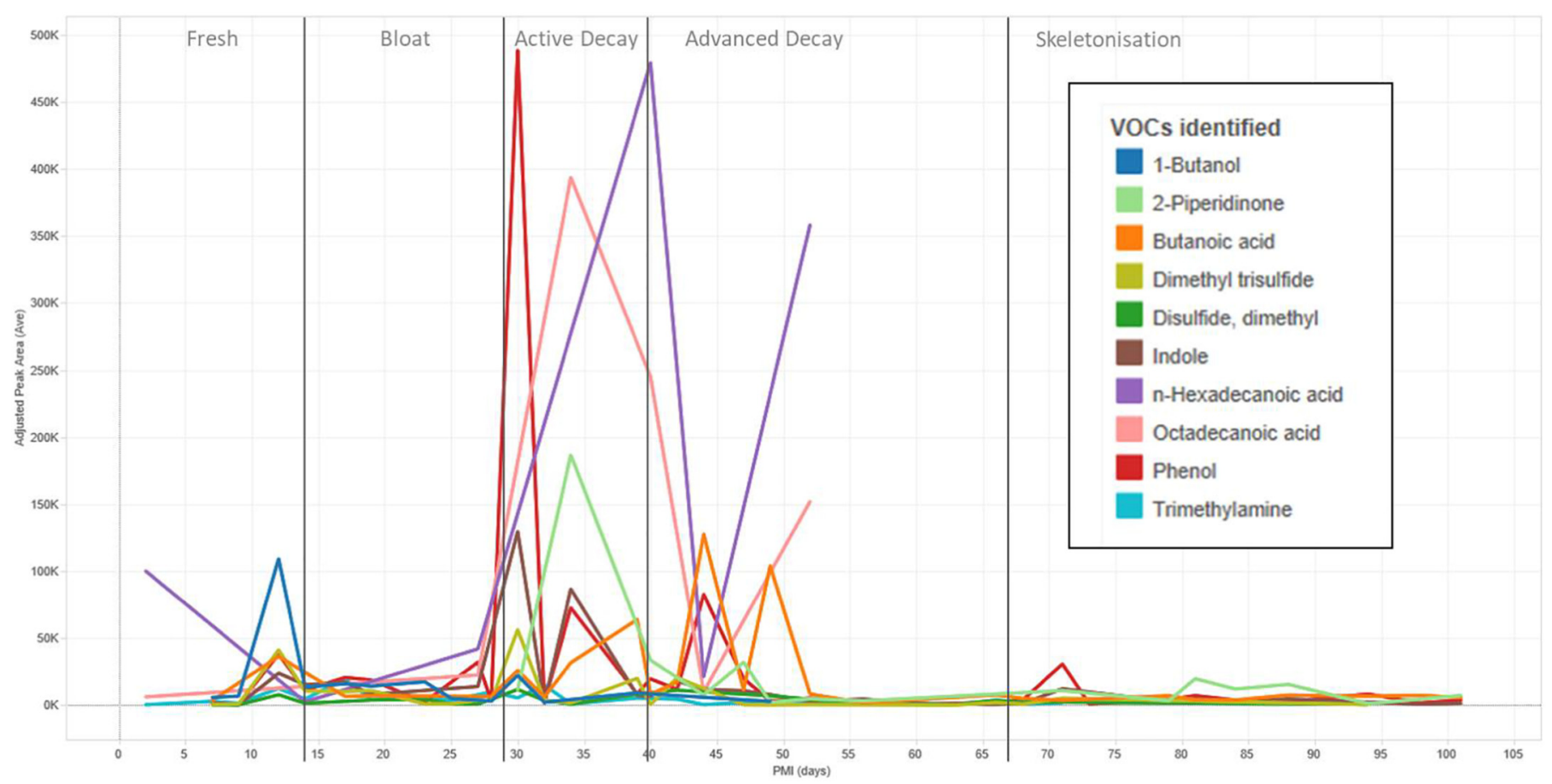

Fig. 1. Average peak areas for the 10 most abundant VOCs detected from the surface-deposited porcine cadavers $(\mathrm{n}=3$ ) against post-mortem interval (days), with decomposition stage marked.

dramatically in the surface-deposited pig boxes. Despite this, when oviposition and maggots were seen during the early float and floating decay stages of the submerged remains, as well as pupae in the bloated deterioration stage, minimal numbers of VOCs were detected with only one VOC detected in the early float stage and only 17 VOCs in the floating decay stage compared to 25 VOCs detected in the Active Decay stage and 31 detected in the Advanced Decay stage of the surface-deposited pigs. This contradicts the idea that maggots were responsible for the presence of some of the VOCs, unless the VOCs they were producing were being absorbed by the water in the submerged pig boxes.

\subsection{Comparison of the VOC profiles from surface-deposited and submerged remains}

Whilst variation of VOC profiles was shown within the deposition types, it was not as great as between the deposition types. Fewer VOCs were observed for the pigs deposited in water $(n=41)$ versus the surface-deposited pigs $(n=74)$ over the whole experimental period.

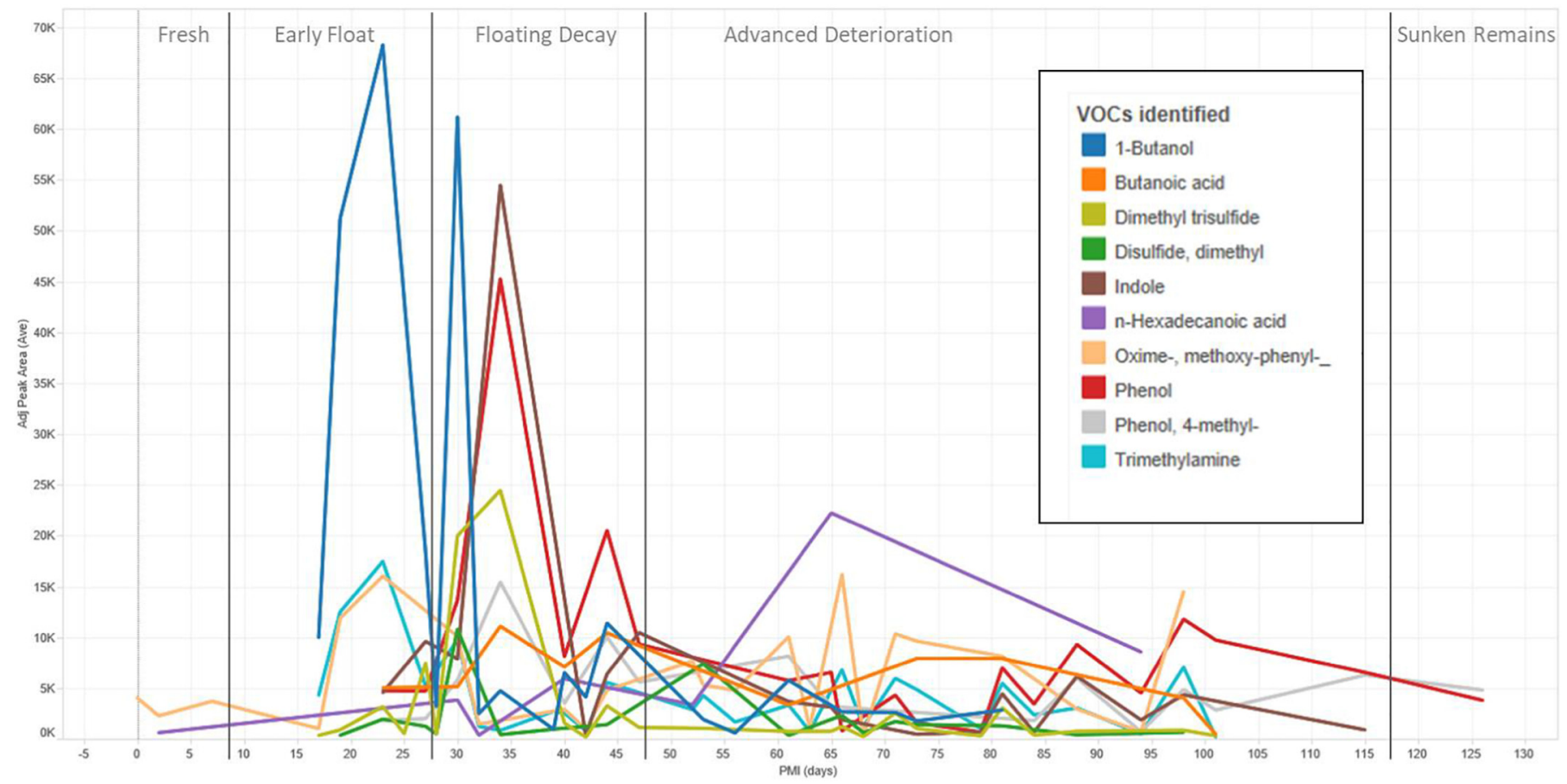

Fig. 2. Average peak areas for the 10 most abundant VOCs detected from the submerged porcine cadavers ( $\mathrm{n}=3$ ) against post-mortem interval (days), with decomposition stage marked. 


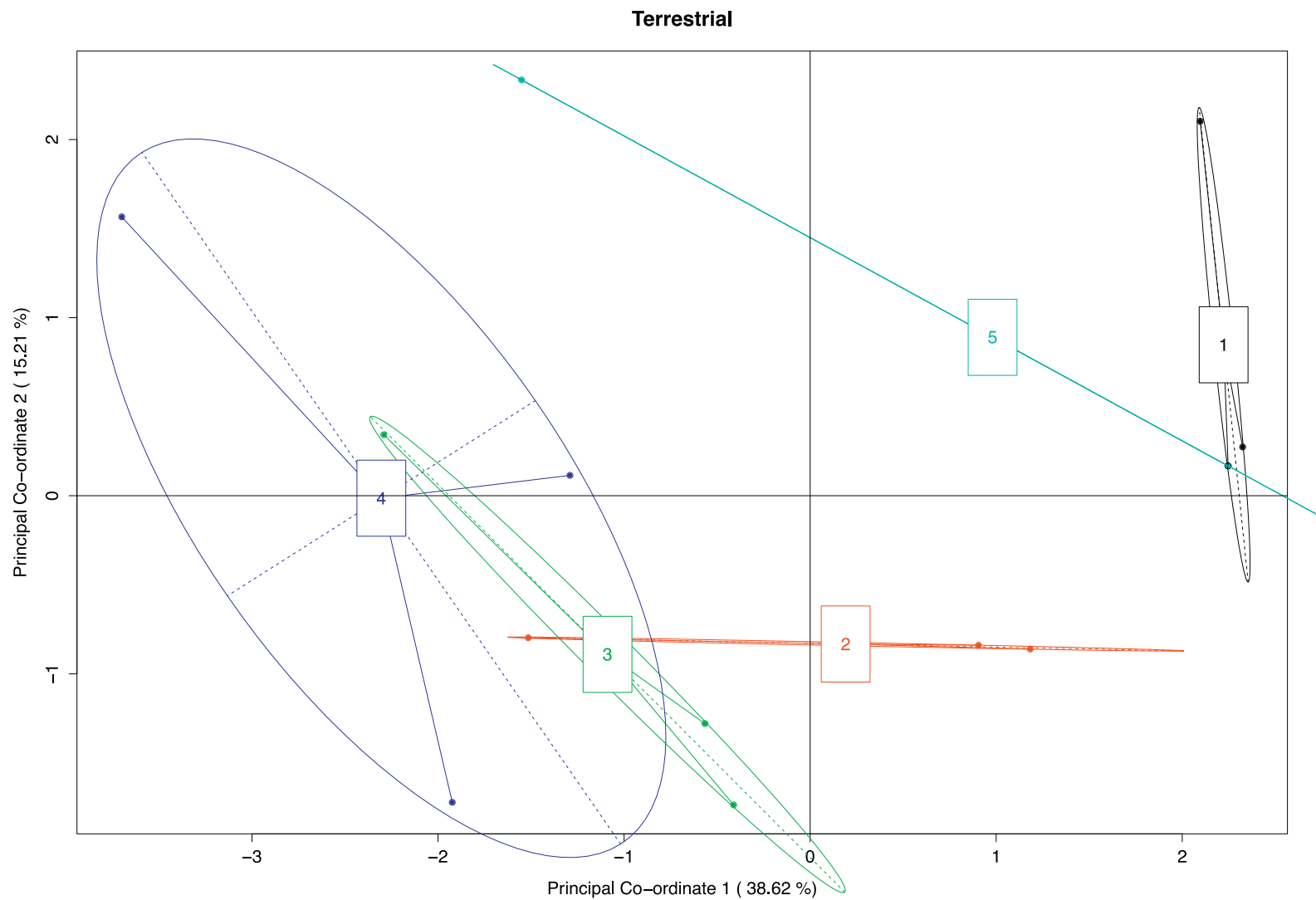

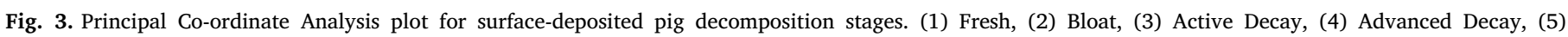
Skeletonisation.

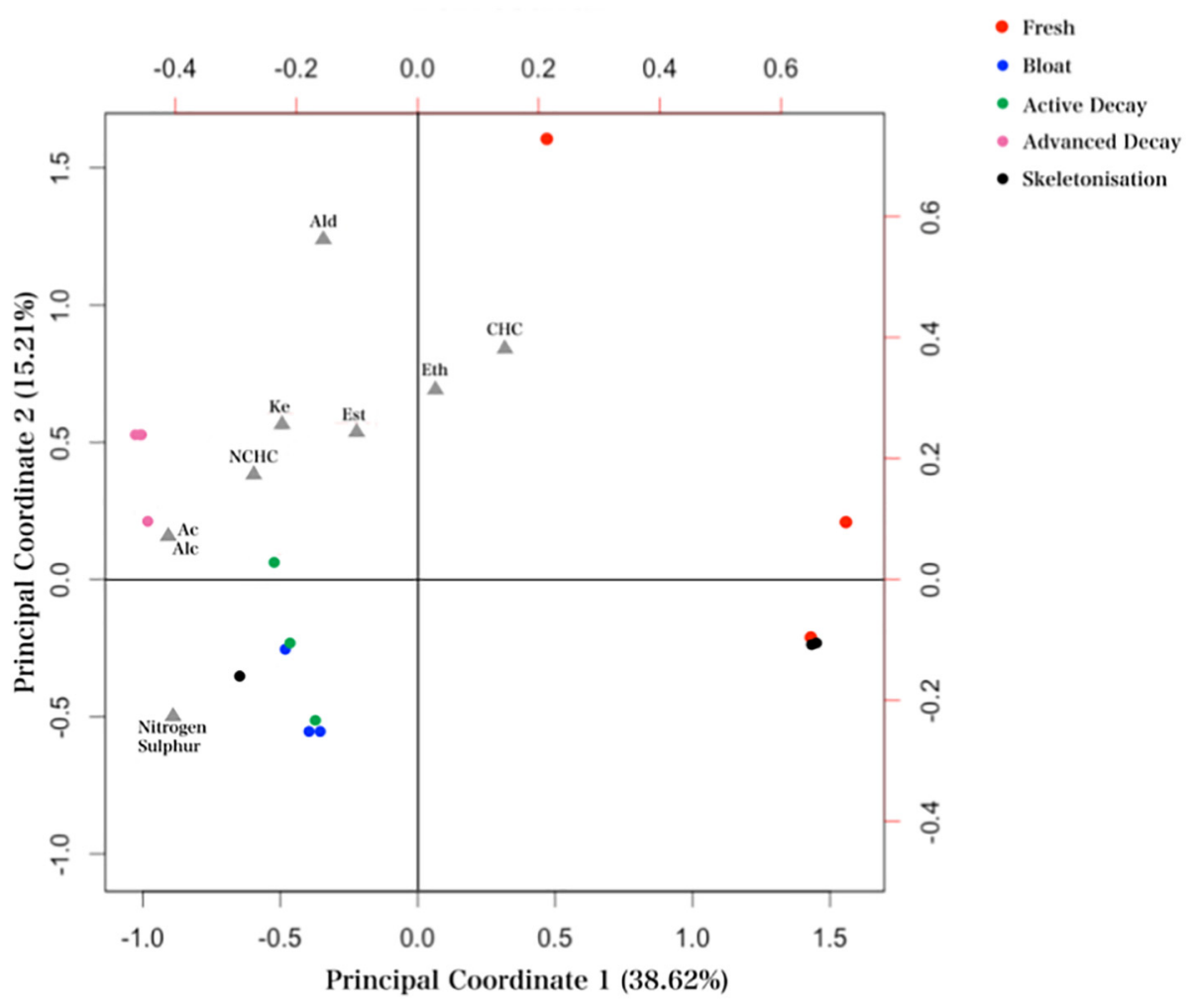

Fig. 4. Principal Co-ordinate Analysis biplot illustrating the relationship of surface-deposited pig decomposition stages (scores) with chemical classes (loadings). (Ac) Acids, (Alc) Alcohols, (Ald) Aldehydes, (CHC) Cyclic hydrocarbons, (Est) Esters, (Eth) Ethers, (Ke) Ketones, (NCHC) Non-cyclic hydrocarbons, (Nitrogen) Nitrogen-containing compounds, (Sulphur) Sulphur-containing compounds. 


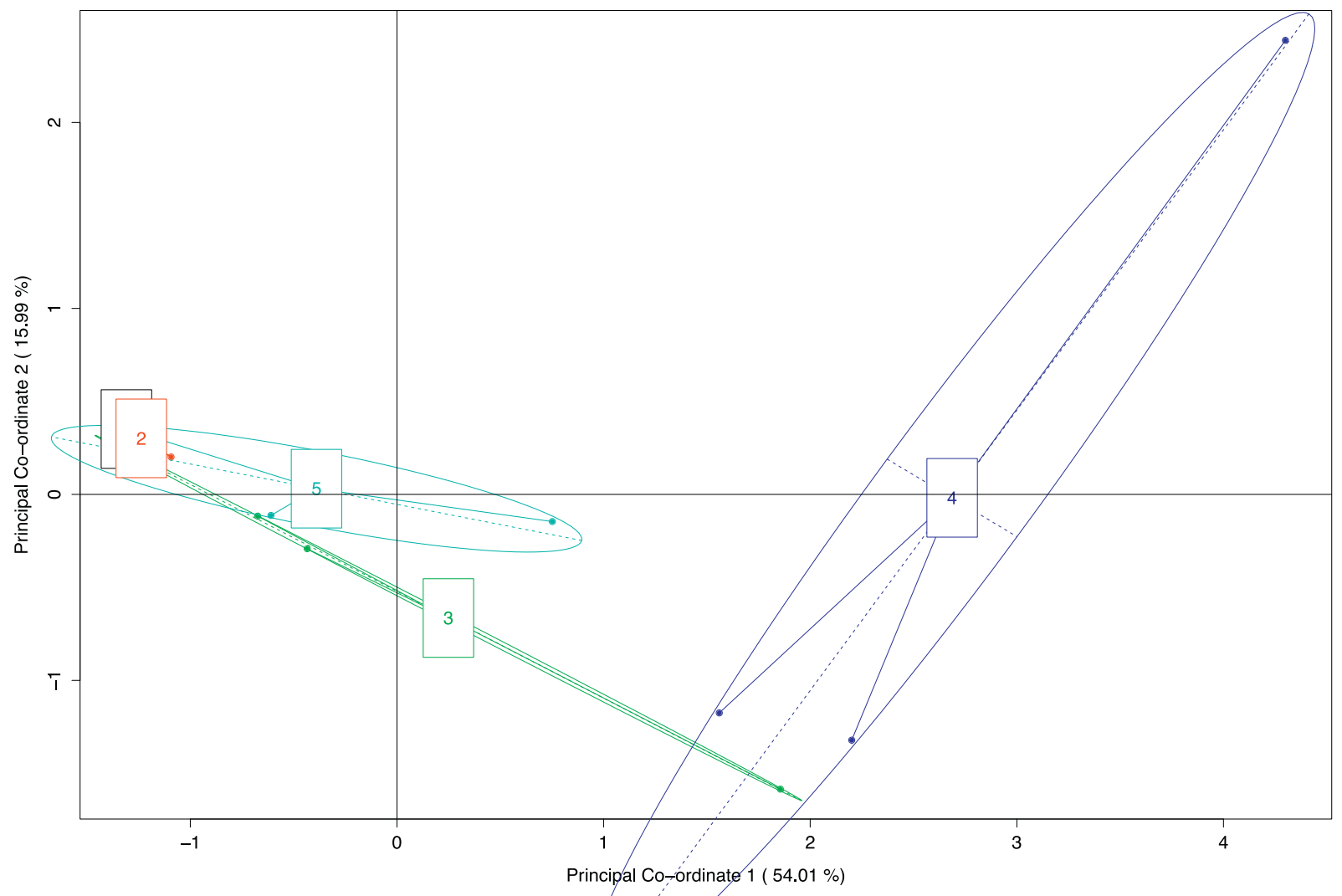

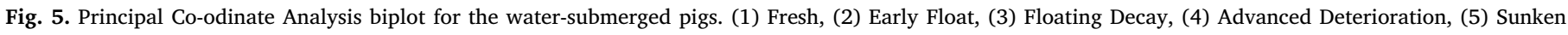
Remains.

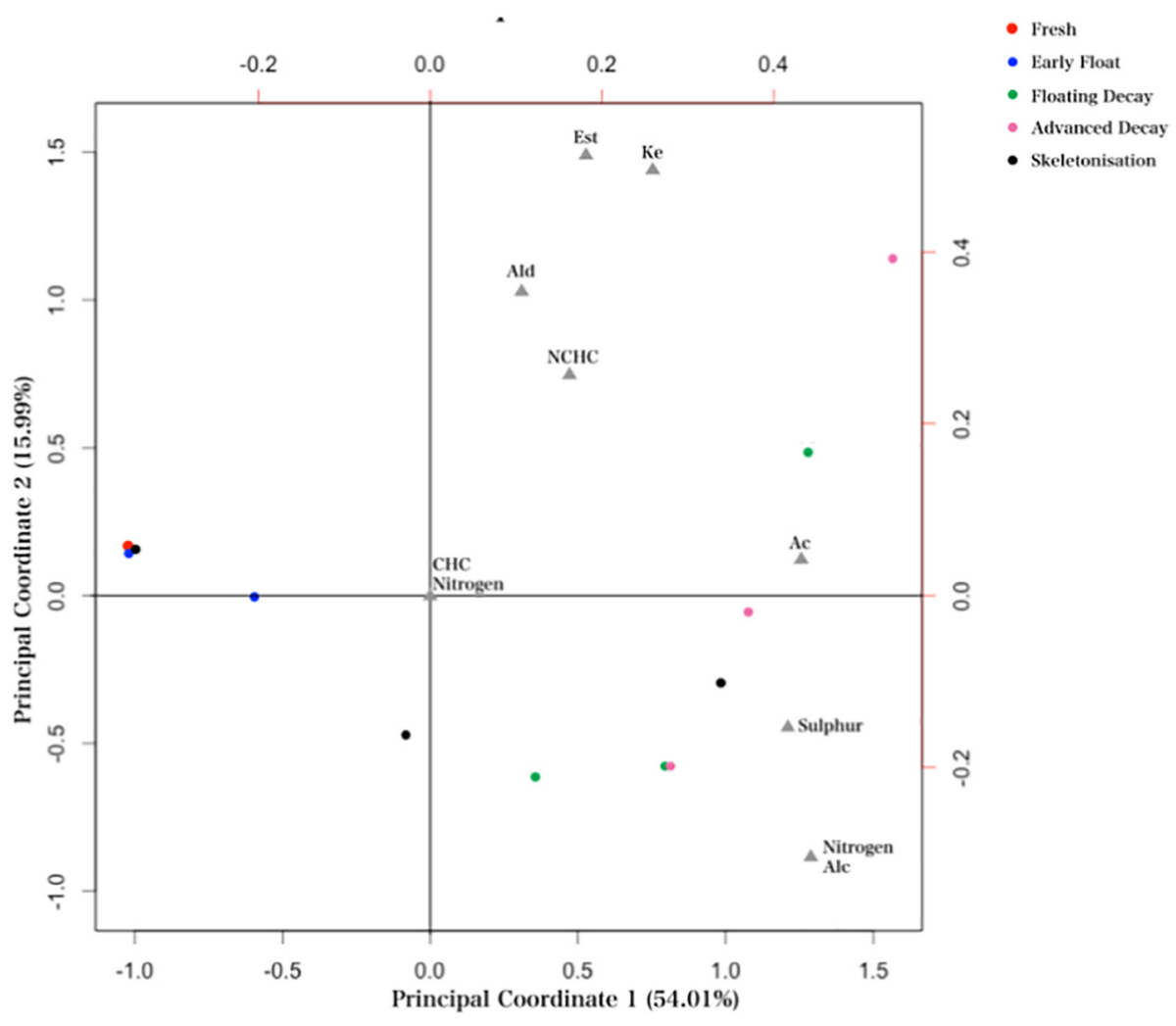

Fig. 6. Principal Co-ordinate Biplot showing the relationship of submerged decomposition stages (scores) to chemical class (loadings). (Ac) Acids, (Alc) Alcohols, (Ald) Aldehydes, (CHC) Cyclic hydrocarbons, (Est) Esters, (Eth) Ethers, (Ke) Ketones, (NCHC) Non-cyclic hydrocarbons, (Nitrogen) Nitrogen-containing compounds, (Sulphur) Sulphurcontaining compounds. 
They were also seen at a reduced frequency in the headspace of the submerged pigs compared to the surface-deposited pigs (Table 5).

The VOC profile from the surface-deposited pigs differed to those from the submerged pigs. Thirty-two of the total VOCs detected were found only from the surface deposition environment. 'High frequency' chemicals (observed $>40 \%$ of samples for duraction of sampling) pigs for the surface-deposited pigs included: 2-methyl butanoic acid, 3-methyl butanoic acid, butanoic acid, phenol, indole, dimethyl disulphide (DMDS) and dimethyl trisulphide (DMTS). A higher diversity of chemicals was detected than from the submerged pigs, especially in the acid and nitrogen-containing compound classes. As with the submerged pigs, acids, alcohols, nitrogen-containing and sulphur-containing compounds made up the majority of classes, with these VOCs showing the highest frequencies throughout the decomposition process. However, these were generally observed early in the decomposition process. For example, sulphur-containing compounds were identified during the bloat phase, peaking in the active decay stage and waning over the subsequent decomposition stages. Different patterns were observed for various compounds within the nitrogen class, with the diversity of amides and pyrazines increasing as decomposition progressed. Indole first appeared during the bloat stage, increasing in frequency and abundance through the subsequent stages. Trimethylamine also first appeared in the bloat stage, increased in frequency in the active decay stage but reduced in frequency throughout the remainder of the decomposition process. PCoA analysis further illustrated this with surfacedeposited pigs, where cyclic hydrocarbons and ethers were indicative of the fresh stage. Nitrogen and sulphur-containing chemicals were closely associated with the bloat stage. Acids, alcohols, non-cyclic hydrocarbons and ketones were all found to be strongly correlated with the advanced decay stage. Active decay overlapped with the bloat and advanced decay stages, with nitrogen and sulphur-containing compounds as well as acids and alcohols present. Lastly, skeletonisation was similar to the bloat stage, as nitrogen- and sulphur-compounds were found in both stages. However, different sulphur- and nitrogen-containing compounds were found to be associated with these two stages. For example, during the bloat stage, trimethylamine, dimethyl disulphide, dimethyl tetrasulphide and methanethiol were all present, but absent during the skeletonisation stage. On the other hand, 2-piperidinone, quinoline and 2-methyll propanamide were present during the skeletonisation stage but absent during bloat.

Long chain acids increased in frequency and diversity throughout the latter stages of the decomposition process, and were observed particularly during the skeletonisation stage of the third surface-deposited pig (A3). This could be associated with remnants of fats $[48,59]$. Greasy, brown deposits were located on all surfaces of the box in A3 and coated all of the skeletal elements. They could have also been directly related to the bones and breakdown of bone marrow, which largely consists of fat and proteins [14].

A smaller number of chemical classes were seen in the headspace of the pigs submerged in water than from the surface-deposited pigs. No cyclic hydrocarbons or ethers were seen in the headspace of the submerged pigs. Only one aldehyde was detected in the headspace of the submerged pigs, namely butanal, which was not detected in the headspace of the surface-deposited pigs. Butanal was also only detected once, so again this could have been a misidentification or environmental contamination. No other aldehydes were detected for the submerged pigs.

Esters were also in a minority chemical class for both the surfacedeposited and submerged pigs. They were only identified in the pigs from second deposition experiment, which could have been due to their larger masses or the higher temperatures to which these pigs were exposed.

Esters were detected later in the decomposition process of the submerged pigs than in the surface-deposited pigs, as were many of the other chemical classes which seen in both the surface and submerged depositions. Acids, alcohols, sulphur and nitrogen compounds made up the bulk of VOC profile from the submerged pigs. These first appeared in the floating decay stage, peaking in the bloated deterioration stage and waning again as the remains began to sink. The latter three classes also contained the individual VOCs which were classed as 'high frequency' chemicals (observed $>20 \%$ of samples over duration of sampling period in submerged pigs). This group included DMTS, TMA, indole, phenol, 4-methyl phenol and butan-1-ol. Finally, ketones and noncyclic hydrocarbons were also represented, although these were present only as a 'low frequency' (observed $<10 \%$ of samples over duration of sampling) group.

PCoA analysis (Figs. 5 and 6) demonstrated that for submerged pigs, chemical classes were further dispersed and less closely related to specific stages of decomposition. Alcohols, acids sulphur-containing and nitrogen-containing compounds were found to be most closely related to both advanced deterioration and the floating decay stage with non-cyclic hydrocarbons, aldehydes, esters and ketones being less closely related. This shows persistence of the detection of these chemical classes over the decomposition stages.

Only five VOCs detected in the headspace of the submerged pigs were novel or specific to water; this included ethyl butanoate, hexyl hexanoate, butanal, 4-methyl pentan-1-ol and 2, 6- bis (1, 10-dimethylethyl), 4- (1-oxopropyl) phenol. These were however only detected at a low frequency ( $<10 \%$ samples for duration of sampling). The remainder of the VOCs $(n=36)$ all had been detected in their surface-deposited counterparts. A lower number of VOCs were detected from the submerged pigs over the duration of the experiment than from the surface-deposited pigs. This was despite the pigs being free to float to the surface, exposing the flesh to the air within the headspace $(\sim 28 \mathrm{~L})$ of the box and allowing insect access. The reduced amount of VOCs associated with the submerged pigs could be down to the solubility of some of the VOCs in water and the physical barrier of the water. For example, short chain carboxylic acids (4C and lower) are highly polar due to the nature of their hydroxyl and carbonyl groups. These groups allow carboxylic acids to form hydrogen bonds with water. Short chain alcohols (with 3C or fewer) also participate in hydrogen bonding with water. Longer chained alcohols are less polar and not as miscible with water, which could help to explain the presence and detectability of butan-1-ol in the headspace of the submerged pigs. The reason for the reduced number of VOCs in the headspace of the box during later stages of decomposition, once the carcasses breached the surface of the water, is harder to explain. It might be assumed that the smaller volume of headspace in comparison to the surface deposition boxes would act to concentrate the VOCs present when the boxes were bunged up. However, this did not occur, as evidenced by the lower numbers of VOCs detected. It is possible the humidity within the boxes in which the pigs were submerged in water had an effect on the efficiency of the SPME fibres used for extraction [60], although this was not tested.

\subsection{Water type}

The water in this study was purposely kept stagnant, with no attempt made to agitate the water in any way prior to collection. In addition, the pigs were not weighted down, allowing them to float and breach the surface. These decisions may have influenced the progression of decomposition and the reslease of VOCs, but may also represent a common scenario in forensic cases. Bodies can be trapped in stagnant water and float as a result of decomposition. Further investigation is required to determine how moving water or complete submersion would affect the VOC profile detected.

If remains are submerged, particularly in stagnant water, it may be necessary for the water to be agitated to aid the release of decomposition VOCs from the water. This may affect Victim Recovery Dogs' ability to pin-point the exact location of remains, although other instrumentation, such as side-scan sonar, may address this problem [61]. Furthermore, the solubility of some VOCs within the water may help to 
explain the phenomenon of dogs "tasting" the water by lapping at the water prior to giving an alert, which has been observed on numerous occasions with different dogs. Further investigation is needed, but currently, it is suggested that this lapping behaviour may aid the dogs' detection of VOCs in the water, and should not be discouraged, and should even be actively encouraged. It may even be appropriate to ensure that this behaviour can be accommodated on searches, for example by deploying a low-hulled boat on water searches, to enable the VR dog to engage in this lapping behaviour.

\section{Conclusions}

This study successfully demonstrated that the profile of VOCs emitted from porcine cadavers submerged in water differs from that of surface-deposited porcine cadavers. Fewer VOCs were observed in the headspace of the pig carcasses submerged in water, even when the carcasses were floating and exposed on the surface of the water.

The results show that an understanding of the effects of different deposition conditions on VOC emissions is vital, particularly when considering their usefulness for aiding the detection of human remains using VR dogs expected to detect remains in a variety of different deposition scenarios and decomposition stages. Practitioners should be aware that differences in odour may affect the performance and/or behaviour of their VR dog; in cases where remains may be submerged, the resulting odour available in the headspace is reduced and differs to remains deposited on land. VR dogs should therefore be exposed to a variety of different odours during training, including different depositions, to maximise their chances of operational success.

\section{Declarations of interest}

None.

\section{Acknowledgements}

This research was funded by the University of Huddersfield. Our grateful thanks go to Ibrahim George and Natasha Reed who provided technical support and also to John Lord who provided pigs for the experiment. Also to Emily Barrett who assisted in the sampling for the duration of the experiments.

\section{References}

[1] RoSPA, The Royal Society of the Prevention of Accidents. Drowning Statistics, [online]. Last accessed 12/09/2015 at: http://www.rospa.com/leisuresafety/ statistics/drowning/.

[2] WHO, Global Report on Drowning, Available online http://www.who.int/violence injury_prevention/global_report_drowning/Final_report_full_web.pdf, (2015) , Accessed date: 6 July 2016.

[3] V. Heaton, A. Lagden, C. Moffatt, T. Simmons, Predicting the postmortem submersion interval for human remains recovered from U.K. waterways, J. Forensic Sci. 55 (2010) 302-307.

[4] H. Soomer, H. Ranta, A. Penttila, Identification of victims from the M/S Estonia, Int. J. Legal Med. 114 (4) (2001) 259-262.

[5] D. Sweet, INTERPOL DVI best-practice standards: an overview, Forensic Sci. Int. $201(1-3)(2010) 18-21$

[6] V. Boumba, K. Ziavrou, T. Vougioklakis, Biochemical pathways generating postmortem volatile compounds co-detected during forensic ethanol analyses, Forensic Sci. Int. 174 (2-3) (2008) 133-151.

[7] S. Paczkowski, F. Maibaum, M. Paczkowska, S. Schütz, Decaying mouse volatiles perceived by Calliphora vicina rob.-Desv, J. Forensic Sci. 57 (6) (2012) 1497-1506, https://doi.org/10.1111/j.1556-4029.2012.02245.x.

[8] S. Stejskal, Death, Decomposition and Detection Dogs: From Science to Scene, CRC Press, 2013.

[9] W. Evans, The Chemistry of Death, Thomas, Springfield, 1963.

[10] M. Saier Jr., Multiple mechanisms controlling carbon metabolism in bacteria, Biotechnol. Bioeng. 58 (2-3) (1998) 170-174.

[11] E. Choe, D.B. Min, Chemistry and reactions of reactive oxygen species in foods, J. Food Sci. 70 (9) (2005) 142-159.

[12] G. Gottschalk, Bacterial Metabolism, Springer-Verlag, New York, 1986.

[13] S. Waksman, R. Starkey, The Soil and the Microbe, Wiley, New York, 1931.

[14] S. Paczkowski, S. Schultz, Post-mortem volatiles of vertebrate tissue, Appl.
Microbiol. Biotechnol. 91 (2011) 917-935.

[15] B. Dent, S. Forbes, B. Stuart, Review of human decomposition processes in soil, Environ. Geol. 45 (4) (2004) 576-585.

[16] A. Rebmann, E. David, M. Sorg, Cadaver Dog Handbook: Forensic Training and Tactics for the Recovery of Human Remains, CRC Press, 2000.

[17] L. DeGreef, K. Furton, Collection and identification of human remains volatiles by non-contact, dynamic airflow sampling and SPME-GC/MS using various sorbent materials, Anal. Bioanal. Chem. 401 (2011) 1295-1307.

[18] S. Stadler, P. Stefanuto, M. Brokl, S. Forbes, J. Focant, Characterization of volatile organic compounds from human analogue decomposition using thermal desorption coupled to comprehensive two-dimensional gas chromatography-time-of-flight mass spectrometry, Anal. Chem. 85 (2) (2013) 998-1005.

[19] H. Gill-King, Chemical and ultrastructural aspects of decomposition, in: W. Haglund, M. Sorg (Eds.), Forensic Taphonomy: The Postmortem Fate of Human Remains, 2nd ed., CRC Press, New York, 1999.

[20] H. Kadota, Y. Ishida, Production of volatile Sulphur compounds by micro-organisms, Annu. Rev. Microbiol. 26 (1972) 127-138.

[21] L. Frederick, R. Starkey, W. Segal, Decomposability of some organic Sulphur compounds in soil, Soil Sci. Soc. Am. J. 21 (3) (1957) 287-292.

[22] D. Wolle, D. Banavara, S. Rankin, Short communication: empirical and mechanistic evidence for the role of pyridoxal-5'-phosphate in the generation of methanethiol from methionine, J. Dairy Sci. 89 (12) (2006) 4545-4550.

[23] H.-W. Chin, R. Lindsay, Ascorbate and transition-metal mediation of methanethiol oxidation to dimethyl disulfide and dimethyl trisulfide, Food Chem. 49 (4) (1994) 387-392.

[24] H.-W. Chin, R. Lindsay, Mechanisms of formation volatile sulfur compounds following the action of cysteine sulfoxide lyases, J. Agric. Food Chem. 42 (1994) 1529-1536.

[25] J. Zahn, A. Dispirito, Y. Do, B.E. Brooks, E. Cooper, J. Hatfield, Correlation of human olfactory responses to airborne concentrations of malodorous volatile organic compounds emitted from swine effluent, J. Environ. Qual. 30 (2) (2001) 624-634

[26] M. Del Castillo-Lozano, S. Mansour, R. Tache, P. Bonnarme, S. Landaud, The effect of cysteine on production of volatile Sulphur compounds by cheese-ripening bacteria, Int. J. Food Microbiol. 122 (3) (2008) 321-327.

[27] R. Janaway, S. Percival, A. Wilson, Decomposition of Human Remains, in: S. Percival (Ed.), Microbiology and Aging: Clinical Manifestations, Humana Press, Springer, 2009.

[28] A. Reynold, G. Cahill, Handbook of Physiology: Adipose Tissue, American Physiological Society, Washington, 1965.

[29] A. Vass, R. Smith, C. Thompson, M. Burnett, D. Worlf, J. Synstalien, N. Dulgerian, B. Eckenrode, Decompositional odor analysis database, J. Forensic Sci. 49 (2004) 760-769.

[30] S. Forbes, B. Stuart, B. Dent, The effect of the burial environment on adipocere formation, Forensic Sci. Int. 154 (1) (2005) 24-34.

[31] D.H. Ubelaker, K.M. Zarenko, Adipocere: what is known after over two centuries of research, Forensic Sci. Int. 208 (2011) 167-172.

[32] T. O'Brien, A. Kuehner, Waxing grave about adipocere: soft tissue change in an aquatic context, J. Forensic Sci. 52 (2) (2007) 294-301.

[33] M. Statheropoulos, C. Spiliopoulou, A. Agapiou, A study of volatile organic com pounds evolved from the decaying human body, Forensic Sci. Int. 153 (2005) 147-155.

[34] A. Vass, Odor mortis, Forensic Sci. Int. 222 (2012) 234-241.

[35] J. Dekeirsschieter, F. Verheggen, M. Gohy, F. Hubrecht, L. Bourguignon, G. Lognay, E. Haubruge, Cadaveric volatile organic compounds released by decaying pig carcasses (Sus domesticus L.) in different biotopes, Forensic Sci. Int. 189 (2009) 46-53.

[36] M. Statheropoulos, A. Agapiou, E. Zorba, K. Mikedi, S. Karma, G. Pallis, C. Eliopoulos, C. Spiliopoulou, Combined chemical and optical methods for monitoring the early decay stages of surrogate human models, Forensic Sci. Int. 210 (2011) 154-163.

[37] C. Brasseur, J. Dekeirsschieter, E. Schotsmans, S. De Koning, A. Wilson, E. Haubruge, J. Focant, Comprehensive two-dimensional gas chromatography-timeof-flight mass spectrometry for the forensic study of cadaveric volatile organic compounds released in soil by buried decaying pig carcasses, J. Chromatogr. A 1255 (2012) 163-170.

[38] J. Dekeirsschieter, P. Stefanuto, C. Brasseur, E. Haubruge, J. Focant, Enhanced characterization of the smell of death by comprehensive two-dimensional gas chromatography-time-of-flight mass spectrometry (GCxGC-TOFMS), PLoS One 7 (2012).

[39] T. Osterkamp, K9 water searches: scent and scent transport considerations, J. Forensic Sci. 56 (2011) 907-912.

[40] S.L. Forbes, K.A. Perrault, Decomposition odour profiling in the air and soil surrounding vertebrate carrion, PLoS One 9 (4) (2014) e95107.

[41] J. Payne, A summer carrion study of the baby pig Sus scrofa Linnaeus, Ecology. 46 (1965) 592-602.

[42] J. Payne, E. King, Insect succession and decomposition of pig carcasses in water, J. Georgia Entomol. Soc. 7 (1972) 153-162.

[43] K. Perrault, T. Rai, B. Stuart, S. Forbes, Seasonal comparison of carrion volatiles in decomposition soil using comprehensive two-dimensional gas chromatographytime of flight mass spectrometry, Anal. Methods 7 (2014) 690-698.

[44] E. Hoffman, A. Curran, N. Dulgerian, R. Stockham, B. Eckenrode, Characterization of the volatile organic compounds present in the headspace of decomposing human remains, Forensic Sci. Int. 186 (2009) 6-13.

[45] C. Hadrich, C. Ortmann, R. Reisch, G. Liebing, H. Ahlers, G. Mall, An electronic body-tracking dog? Int. J. Legal Med. 124 (2010) 43-47.

[46] S.L. Forbes, K.A. Perrault, P.-H. Stefanuto, K.D. Nizio, J.-F. Focant, Comparison of 
the decomposition VOC profile during winter and summer in a moist, mid-latitude (Cfb) climate, PLoS One 9 (11) (2014) e113681.

[47] E. Rosier, E. Cuypers, M. Dekens, R. Verplaetse, W. Develter, W. Van De Voorde, D. Maes, J. Tytgat, Development and validation of a new TD-GC/MS method and its applicability in the search for human and animal decomposition products, Anal. Bioanal. Chem. 406 (2014) 3611-3619.

[48] L. Swann, G.E. Chidlow, S. Forbes, S.W. Lewis, Preliminary studies into the characterization of chemical markers of decomposition for geoforensics, J. Forensic Sci. 55 (2) (2010) 308-314.

[49] A. Agapiou, E. Zorba, K. Mikedi, L. McGregor, C. Spiliopoulou, M. Statheropoulos, Analysis of volatile organic compounds released from the decay of surrogate human models simulating victims of collapsed buildings by thermal desorption-comprehensive two-dimensional gas chromatography-time of flight mass spectrometry, Anal. Chim. Acta 883 (2015) 99-108.

[50] S. Paczkowski, S. Nicke, H. Ziegenhagen, S. Schutz, Volatile emission of decomposing pig carcasses (sus scrofa domesticus L.) as an indicator for the postmortem interval, J. Forensic Sci. 60 (S1) (2015) 130-137.

[51] M. Statheropoulos, A. Agapiou, C. Spiliopoulou, G.C. Pallis, E. Sianos, Environmental aspects of VOCs evolved in the early stages of human decomposition, Sci. Total Environ. 385 (2007) 221-227.

[52] N. Akdeniz, J.A. Koziel, H.K. Ahn, T.D. Glanville, B.P. Crawford, D.R. Raman, Laboratory scale evaluation of volatile organic compound emissions as indication of swine carcass degradation inside biosecure composting units, Bioresour. Technol. 101 (1) (2010) 71-78.

[53] A.A. Vass, R.R. Smith, C.V. Thompson, M.N. Burnett, N. Dulgerian, B.A. Eckenrode, Odor analysis of decomposing buried human remains, J. Forensic Sci. 53 (2008) 384-391.

[54] C. Frederickx, J. Dekeirsschieter, Y. Brostaux, J.-P. Wathelet, F.-J. Verheggen, E. Haugruge, Volatile organic compounds released by blowfly larvae and pupae: new perspectives in forensic entomology, Forensic Sci. Int. 219 (2012) 215-220.

[55] C. Von Hoermann, S. Steiger, J. Miller, M. Ayasse, Too fresh is unattractive! The attraction of newly emerged Nicrophorus vespilloides females to odour bouquets of large cadavers at various stages of decomposition, PLoS One 8 (2013).

[56] H. Johansen, M. Solum, G. Knudsen, E. Hagvar, H. Norli, A. Aak, Blow fly responses to semiochemicals produced by decaying carcasses, Med. Vet. Entomol. 28 (2014) 26-34.

[57] J. Kasper, R. Mumm, J. Ruther, The composition of carcass volatile profiles in relation to storage time and climate conditions, Forensic Sci. Int. 223 (2012) 64-71.

[58] D. Charabidze, B. Bourel, V. Hedouin, D. Gosset, Repellent effect of some household products on fly attraction to cadavers, Forensic Sci. Int. 189 (1-3) (2009) 28-33.

[59] L. Swann, S. Forbes, S.W. Lewis, Observations of the temporal variation in chemical content of decomposition fluid: a preliminary study using pigs as a model system, Aust. J. Forensic Sci. 42 (2009) 199-210.

[60] M. Alpendurada, Solid-phase microextraction: a promising technique for sample preparation in environmental analysis, J. Chromatogr. A 889 (1-2) (2000) 3-14.

[61] C.A. Healy, J.J. Schultz, K. Parker, B. Lowers, Detecting submerged bodies: controlled research using side-scan sonar to detect submerged proxy cadavers, J. Forensic Sci. 60 (3) (2015) 743-752.

[62] E. Catts, M. Goff, Forensic entomology in criminal investigations, Annu. Rev. Entomol. 37 (1992) 253-272.

[63] G. Anderson, S. Van Laerhoven, Initial studies on insect succession on carrion in southwestern British Colombia, J. Forensic Sci. 41 (4) (1996) 617-625.

[64] K. Schoenly, N. Haskell, D. Mills, C. Bieme-Ndi, K. Larsen, Y. Lee, Recreating death's acre in the school yard: using pig carcasses as model corpses, Am. Biol. Teach. 68 (7) (2006) 402-410.

[65] A. Vass, Beyond the grave -understanding human decomposition, J. Microbiol. 28 (2001) 190-192. 